\title{
Bassins versants du Loup, de la Cagne et du Malvan
}

Cédric Lepère, Laurence Lautier et Emmanuel Pellegrino

\section{QpenEdition Journals}

Édition électronique

URL : http://journals.openedition.org/adlfi/6606

ISSN : 2114-0502

Éditeur

Ministère de la culture

Référence électronique

Cédric Lepère, Laurence Lautier et Emmanuel Pellegrino, «Bassins versants du Loup, de la Cagne et du Malvan », ADLFI. Archéologie de la France - Informations [En ligne], Provence-Alpes-Côte d'Azur, mis en ligne le 01 mars 2007, consulté le 01 mai 2019. URL : http://journals.openedition.org/adlfi/6606

Ce document a été généré automatiquement le 1 mai 2019.

(C) Ministère de la Culture et de la Communication, CNRS 


\title{
Bassins versants du Loup, de la Cagne et du Malvan
}

\author{
Cédric Lepère, Laurence Lautier et Emmanuel Pellegrino
}

Identifiant de l'opération archéologique : 8453

Date de l'opération : 2007 (PC) ; 2007 (PI)

Inventeur(s) : Lepère Cédric (AUT) ; Lautier Laurence (AUT) ; Pellegrino Emmanuel (AUT)

1 Une campagne de prospection inventaire a été effectuée pendant trois mois, dans les bassins-versants de la Cagne, du Loup et du Malvan qui regroupent les communes de Cagnes-sur-Mer, Villeneuve-Loubet, La Colle-sur-Loup, Saint-Paul-de-Vence, Vence, Saint-Jeannet, Bezaudun, Tourrettes-sur-Loup, Roquefort-les-Pins, Le Rouret, Bar-surLoup, Gourdon, Courmes, Course-goules, Gréolières, Cipières, Caussols et Andon.

2 Cette opération s'inscrit dans le cadre du programme de recherche «Histoire et modélisation des dynamiques socioenvironnementales holocènes des paysages fluviaux de la Côte d'Azur» (ATIP Jeunes Chercheurs du CNRS), coordonné par Frédérique Bertoncello. Son objectif est de retracer l'évolution des hydrosystèmes de l'Argens (Var) et $\mathrm{du}$ Loup, de la Cagne et du Malvan (Alpes-Maritimes) afin d'appréhender, d'une part, les répercussions de la mobilité des paysages sur l'occupation humaine et, d'autre part, l'impact de l'occupation humaine sur les paysages et les écosystèmes.

3 Afin de comprendre les dynamiques du peuplement de la Préhistoire à l'époque moderne et d'élaborer une base de données centrée sur les bassins du Loup, de la Cagne et du Malvan, nous avons prospecté les sites déjà inventoriés, de manière à vérifier leur localisation, préciser leur superficie, découvrir du mobilier permettant d'affiner leur datation et améliorer leur description. Parallèlement, le mobilier conservé dans les dépôts du musée d'art et d'histoire de Provence de Grasse, du CÉPAM et de l'IPAAM, a été revu et inventorié. 
4 Sur les dix-huit communes prospectées, nous avons pu vérifier onze sites occupés au Paléolithique, soixante-douze au Néolithique, quatre à l'Épipaléolithique, un au Mésolithique, vingt à l'âge du Bronze, trente-sept à l'âge du Fer, quarante-huit au cours de l'Antiquité, vingt au Moyen Âge et cent vingt-trois durant les périodes moderne et/ou contemporaine.

5 LAUTIER Laurence, LEPÈRE Cédric et PELLEGRINO Emmanuel

6 Nous remercions Frédérique Bertoncello, coordinatrice de l'ATIP, Michel Dubar (CÉPAM), Thibault Lachenal et Jean-Claude Poteur (inventaire du Patrimoine du Conseil général des Alpes-Maritimes) qui ont déterminé les matériaux de mouture, les céramiques de l'âge du Bronze et les céramiques médiévales et modernes, Suzanne Roscian pour son aide dans l'élaboration de la base de données, Joëlle Dujardin et Claude Salicis qui nous ont facilité l'accès au mobilier.

INDEX

operation Projet collectif de recherche (PCR), Prospection inventaire (PI)

Index chronologique : Antiquité romaine, ép. contemporaine, Moyen Âge**, Épipaléolithique, Mésolithique, Néolithique, âge du Bronze, âge du Fer

\section{AUTEURS}

CÉDRIC LEPÈRE

LAURENCE LAUTIER

EMMANUEL PELLEGRINO 